\title{
Surgical cryoablation as an option for small renal masses in patients who are not ideal partial nephrectomy candidates: intermediate-term outcomes
}

\author{
Venu Chalasani, MBBS, FRACS; Carlos H. Martinez, MD; Darwin Lim, MD; Mazen Abdelhady, MSc, MD; \\ Joseph L. Chin, MD, FRCSC
}

\section{Abstract}

Objective: There has been increasing interest in surveillance and ablative techniques for small renal masses (SRM), given the increasing number being diagnosed at smaller sizes. Of the currently available ablative techniques, radiofrequency ablation and cryoablation have been the popular ones. We describe our intermediate-term outcomes with using cryoablation for SRM in patients who were not ideal candidates for partial nephrectomy.

Materials and methods: Nineteen patients treated with cryoablation were included. Patients with renal lesions $<4 \mathrm{~cm}$ were considered for cryoablation, and all patients were treated between 2002 and 2007. Access was either laparoscopic (transperitoneal) or via open surgical techniques. From 2002 to 2004, the CryoCare System (Endocare, Inc., Irvine, CA) was used, with probe sizes ranging from 3 to $5 \mathrm{~mm}$. Before 2004, the SeedNet system (Galil Medical, Arden Hills, MN) was used, with 17-gauge $(1.47 \mathrm{~mm})$ IceRod cryoneedles. Recurrence-free survival (RFS) and overall survival (OS) were calculated using Kaplan Meier methodology.

Results: The mean age was 56.7 years. The mean tumour size was $2.6 \mathrm{~cm}$ (range 1.2-4.0 cm). There were no intraoperative or postoperative complications in the 19 patients. One patient has been lost to follow-up; mean follow up was 41.6 months (range 7-84 months) in the cohort. Recurrence, defined as either increase in size of lesion or enhancement on follow-up imaging, was seen in 4 patients. There was 1 non-cancer specific death, and 1 cancer specific death.

Conclusions: The 4-year RFS rate and OS rate were $83.6 \%$ and $94.1 \%$, respectively, in patients with SRM who were unsuitable for partial nephrectomy.

Can Urol Assoc J 2010;4(6):399-402

\section{Résumé}

Objectif : Le diagnostic étant de plus en plus précoce, on note un intérêt croissant pour les techniques de surveillance et d'ablation des petites masses rénales. Parmi les techniques actuelles, I'ablation par radiofréquence et la cryoablation sont les plus utilisées. Nous présentons ici nos résultats à moyen terme avec la cryoablation de petites masses rénales chez des patients à qui la néphrectomie partielle ne convenait pas.

Matériel et méthodologie : Dix-neuf patients traités par cryoablation ont été inclus. Les patients présentant des lésions rénales de $<4 \mathrm{~cm}$ étaient considérés, et tous les patients ont été traités entre 2002 et 2007. L'abord se faisait par laparoscopie (transpéritonéale) ou par chirurgie ouverte. De 2002 à 2004, on a eu recours au système CryoCare (Endocare, Inc., Irvine, Calif.), avec des sondes de 3 à 5 mm. Avant 2004, on utilisait le système SeedNet ${ }^{\mathrm{MC}}$ (Galil Medical, Arden Hills, Minn.), avec des cryo-aiguilles IceRod de calibre 17 $(1,47 \mathrm{~mm})$. Les taux de survie sans récurrence (SSR) et de survie globale (SG) ont été calculés par la méthode de Kaplan Meier.

Résultats : L'âge moyen était de 56,7 ans; la taille moyenne des tumeurs était de 2,6 cm (de 1,2 à 4,0 cm). Aucun des 19 patients n'a présenté de complication intra ou postopératoire. Un patient a été perdu de vue lors du suivi. La durée moyenne du suivi était de 41,6 mois (7 à 84 mois). Quatre patients ont présenté une récurrence, définie comme une augmentation de la taille de la lésion ou une lésion plus visible lors des épreuves d'imagerie de suivi. Un patient est décédé de causes non liées au cancer, et un autre, des suites du cancer.

Conclusions : Les taux de SSR et de SG après 4 ans étaient de $83,6 \%$ et de $94,1 \%$, respectivement, chez des patients avec petites masses rénales à qui une néphrectomie partielle ne convenait pas.

\section{Introduction}

Between 1996 to 2005, the incidence of renal cell carcinoma (RCC) in Canada has been rising (especially in young women), possibly due to the rising prevalence of obesity and improved detection. The most recent Canadian cancer statistics show that for 2009 there will be an expected 4600 cases, with an expected 1600 deaths. ${ }^{1}$

There has been increasing interest in surveillance and ablative techniques for small renal masses, given the increasing number being diagnosed at smaller sizes. ${ }^{2}$ Furthermore, histopathology results show that $20 \%$ to $27.9 \%$ of clinical T1 renal masses are benign in large partial nephrectomy series. ${ }^{3,4}$ Of the currently available ablative techniques, interest is on radiofrequency ablation and cryoablation. Both of these ablative techniques can be performed percutaneously or via surgical techniques (either open or laparoscopic). With the main alternative to ablative techniques being either radical nephrectomy or partial nephrectomy, the perceived benefits of ablative techniques include lower postoperative morbidity and improved renal preservation. 
The main disadvantage to ablative techniques is the lack of histopathological confirmation of complete ablation, with patients requiring careful follow-up. There have been few reports describing the intermediate-term efficacy of laparoscopic cryoablation for renal masses. We describe our medium-term outcomes using cryoablation for small renal masses in patients who were not ideal candidates for partial nephrectomy.

\section{Methods}

Since 2002, renal cryoablation has been offered at the University of Western Ontario for patients who were not ideal surgical candidates with renal lesions $<4 \mathrm{~cm}$. Between 2002 and 2007, 19 patients were treated with cryoablation. Indications for cryoablation were medical comorbidities in 9 patients (American Society of Anesthesiologists [ASA] 3) and surgical considerations in the other 10 (including solitary kidneys, previous renal surgery and anatomical considerations related to partial nephrectomy). Access was either laparoscopic (11 patients) or via open surgical techniques (8 patients).

Most patients underwent a biopsy prior to starting cryoablation for diagnostic purposes, unless prior imaging had indicated a definitive diagnosis (e.g., if the prior imaging was consistent with angiomyolipoma, then biopsy was not undertaken). Trucut biopsy was performed after mobilization of the kidney, and prior to cryoablation.

Before 2004, the CryoCare system (Endocare, Inc., Irvine, CA) (which is argon based) was used, with probe sizes ranging from $3 \mathrm{~mm}$ to $5 \mathrm{~mm}$. Subsequent to 2004, the SeedNet system (Galil Medical, Arden Hills, MN) was used, with $1.47 \mathrm{~mm}$ IceRods. Cryoablation was performed either by open or laparoscopic access. In all cases, real-time ultrasound guidance was used to localize the tumour and to monitor the progression of iceball formation, which is very visible as a hyperechoic edge. A double freeze-thaw cycle was used.

Patients were followed-up using serial imaging, usually with computed tomography (CT) scanning or ultrasound. For patients with renal insufficiency, magnetic resonance imaging was used in place of CT scanning. Lack of enhancement and stability or reduction in size of the lesion on follow-up imaging was considered a successful cryoablation. ${ }^{5}$

Statistical analysis was performed using StatalC 10.1 (StatCorp, College Station, TX), and survival was calculated using Kaplan Meier techniques. A paired students t-test was used to test for any significant differences between preoperative and postoperative serum creatinine levels.

\section{Results}

The mean age was 56.7 years (range 27-78), and there were 6 females and 13 males. The mean tumour size was $2.6 \mathrm{~cm}$ (range 1.2-4.0). In total, 21 renal masses were ablated in 19 patients (Table 1 ).

Eight patients underwent open cryoablation, with the remaining 11 patients had transperitoneal laparoscopic cryoablation. None of the laparoscopic group required conversion to an open procedure. Seven tumours were located at the lower pole, 7 were interpolar and 5 tumours were located at the upper pole. There were no intraoperative complications. The mean hospital stay was 4.8 days for the open surgical group, and 2.6 days for the laparoscopic group. No patient required a blood transfusion and there was no statistically significant difference between preoperative and postoperative serum creatinine levels ( 89 vs. $98 ; p=0.29$ ). Biopsy was performed intra-operatively in 14 patients prior to cryoablation. The biopsy showed RCC in 9 cases $(64 \%)$, benign histology in 4 cases, and was non-diagnostic in 1 case.

At the mean follow-up of 41.6 months, 1 patient was lost to follow-up.

Recurrence, defined as either an increase in size of the lesion or enhancement on follow-up imaging, was seen in 4 patients. Recurrences occurred at 28 months, 37 months, 54 months and 55 months, respectively; the mean time to recurrence was 43.5 months. The 4 -year recurrence-free survival rate was $83.6 \%$. One patient with local recurrence eventually developed metastatic disease and died, and there was 1 non-cancer related death. The 4-year overall survival rate was $94.1 \%$. No patient developed renal failure during follow-up.

\section{Discussion}

Cryoablation dates back to the Egyptian and Ancient Greek civilizations. Modern cryoablation began in 1961, when

\begin{tabular}{lc}
\hline \multicolumn{2}{l}{ Table 1. Preoperative characteristics } \\
\hline No. of patients & 19 \\
\hline Mean age $\pm(\mathrm{SD})$ & $56.7 \pm(16.0)$ yrs \\
\hline Mean ASA & 2.4 \\
\hline $\begin{array}{l}\text { No. of patients with } 2 \text { masses } \\
\text { ablated }\end{array}$ & 2 \\
\hline Mean tumour diameter \pm (SD) & $2.6 \pm(0.7) \mathrm{cm}$ \\
\hline Distribution of tumours & $37 \%$ \\
\hline Lower pole & $37 \%$ \\
\hline Interpolar & $26 \%$ \\
\hline Upper pole & 3 \\
\hline $\begin{array}{l}\text { No. of patients with solitary } \\
\text { kidneys }\end{array}$ \\
\hline SD = standard deviation; ASA = American Society of Anesthesiologists score. \\
\hline
\end{tabular}


neurosurgeon Irving Cooper and his colleagues performed a stereotactic thalmectomy using liquid nitrogen. In 1995, Uchida and colleagues described the use of percutaneous renal cryoablation on 2 patients with advanced RCC. ${ }^{6}$ Porcine work in 1998 established a lethal temperature of $-19.4^{\circ} \mathrm{C}$ in the kidney. ${ }^{7}$ The mechanism of action of renal cryoablation is believed to be a combination of cell rupture, necrosis (both primary and secondary) and freezing induced apoptosis in cells with intact membranes. Recent work using the human renal cell cancer line 786-O has shown that freezing to below $-20^{\circ} \mathrm{C}$ causes complete cell death within all cells, ${ }^{8}$ unlike work in prostate cancer cells which has shown that some cells survive at $-80^{\circ} \mathrm{C} .{ }^{9}$

Our cohort had good outcomes following renal cryoablation, with a 4-year overall survival of $94.1 \%$, and a 4-year recurrence-free survival rate of $83.6 \%$ at a median follow-up of 41.6 months. This outcome is comparable to published recurrence-free survival results, which ranged from $93.3 \%$ to $95.8 \%{ }^{10,11}$ The major limitation with the published literature is the short follow-up, with most studies ranging from 6 to 24 months; there are limited published series with mean follow-up exceeding 3 years (Table 2). ${ }^{12-14} \mathrm{~A}$ recent meta-analysis found the mean weighted follow-up of the published cryoablation literature to be 18.3 months. ${ }^{2}$

This present study demonstrated the low morbidity of renal cryoablation, especially compared to the published complication rates of partial nephrectomy..$^{15}$ However, we noted that other published complications of renal cryoablation include bleeding requiring transfusion, bowel injury and renal fracture. Despite the absence of complications within our series, it is difficult to draw conclusions due to the low number of patients in our report, which is one of the limitations of our study. A recently published European multicentre study found that Clavien grade $\geq 3$ complications occurred in only $4 \%$ of cases. ${ }^{16}$

Newer developments in minimally invasive urology, such as laparo-endoscopic single-site surgery (LESS) ${ }^{17,18}$ or natural orifice transluminal endoscopic surgery (NOTES), ${ }^{18}$ continue to miniaturize instruments and are suited to procedures, such as renal cryotherapy. Further refinements in instrumentation or careful patient selection are required prior to the adoption of these technologies. Nevertheless, with evidence mounting for the need to preserve as much renal parenchyma as possible, ablative technologies which require no clamping of the renal hilum will continue to play a role in the urological armamentarium; therefore, the development of newer technologies, such as LESS, should be encouraged within a controlled and regulated environment.

Surprisingly, our 2 recurrences occurred late, both after 4 years of follow-up. In the published literature, most recurrences occur early, typically within the first 2 years. These 2 late recurrences serve to underscore one of the current controversies in renal cryotherapy - the optimal follow-up
Table 2. Published series with mean follow up exceeding 3 years

\begin{tabular}{lccccc}
\hline Authors & Year & $\begin{array}{c}\text { Patients } \\
\text { (n) }\end{array}$ & $\begin{array}{c}\text { Follow-up } \\
\text { (mos) }\end{array}$ & $\begin{array}{c}\text { Recurrences } \\
(\%)\end{array}$ & $\begin{array}{c}\text { Overall } \\
\text { survival }\end{array}$ \\
\hline Davol $^{12}$ & 2006 & 48 & 64 & $5(12.5 \%)$ & $89.6 \%$ \\
\hline Weld $^{13}$ & 2007 & 31 & 45.7 & $1(3.2 \%)$ & $\mathrm{N} / \mathrm{R}$ \\
\hline Gill $^{14}$ & 2005 & 56 & 36 & $2(3.6 \%)$ & $89 \%$ \\
\hline
\end{tabular}

schedule for these patients.

The ideal schedule is yet to be determined. Some groups have advocated using repeat biopsy with serial imaging; others have used serial imaging alone. ${ }^{5}$ The problems with renal biopsy are well-known. These problems preclude its routine use in clinical practice, in that a negative biopsy does not exclude cancer, and also because of the difficulty for pathologists to distinguish between chromophobic RCC and oncocytoma. Furthermore, in the context of a positive biopsy with no growth on serial imaging, some would argue that such patients could be effectively managed with active surveillance; currently a randomized clinical trial is underway to study the outcomes of surveillance for small renal masses. We would recommend long-term imaging followup, exceeding 5 years at the minimum, based on our pattern of recurrences.

Limitations of this study include its retrospective nature, the lack of clearly defined inclusion criteria, and the lack of repeat biopsies on patients after cryoablation to confirm the absence of viable tumour. However, a negative biopsy does not exclude cancer, and so we kept our patients on a follow-up schedule which was imaging-based. Furthermore, current thinking on the small renal mass has changed from $2002,{ }^{19}$ such that some patients may be candidates for active surveillance.

Percutaneous renal cryoablation has been increasingly reported in the last 5 years, with comparable efficacy rates to laparoscopic cryoablation, ${ }^{20,21}$ although more than one treatment session may be needed. The morbidity and costs may be lower with the percutaneous approach, ${ }^{21,22}$ and in some institutions percutaneous renal cryoablation has become the preferred treatment modality for the asymptomatic small renal mass. ${ }^{10}$ In most institutions, however, the techniques of laparoscopic and percutaneous cryoablation are complementary, with the percutaneous approach being used for posteriorly located tumours and the laparoscopic approach being used for the remainder. ${ }^{23}$ Percutaneous cryoablation was not available in the early part of the study period at our institution; however, it is now part of our armamentarium. Novel ideas, such as using injected air or saline to displace vital structures (such as bowel), have been used to expand the use of percutaneous renal cryotherapy. ${ }^{24}$ 


\section{Conclusion}

Further prospective studies with longer follow up are needed to determine the exact role of cryoablation to treat small renal masses; however, preliminary data are encouraging. The 4-year recurrence-free survival rate was $83.6 \%$ and the 4-year overall survival rate was $94.1 \%$. Long-term follow-up is required in these patients, as demonstrated by the mean time to recurrence of 43.5 months.

Division of Urology, University of Western Ontario, London, ON

Competing interests: None declared.

This paper has been peer-reviewed.

\section{References}

1. Canadian Cancer Society's Steering Committee: Canadian Cancer Statistics 2009. Toronto: Canadian Cancer Society, 2009.

2. Kunkle DA, Egleston BL, Uzzo RG. Excise, ablate or observe: the small renal mass dilemma-a meta-analysis and review. J Urol 2008;179:1227-33.

3. Crispen PL, Booriian SA, Lohse CM, et al. Outcomes following partial nephrectomy by tumour size. J Urol 2008;180:1912-7.

4. Gill IS, Kavoussi LR, Lane BR, et al. Comparison of 1,800 laparoscopic and open partial nephrectomies for single renal tumours. J Urol 2007;178:41-6.

5. Beemster $\mathrm{P}$, Phoa $\mathrm{S}$, Wijkstra $\mathrm{H}$, et al. Follow-up of renal masses after cryosurgery using computed tomography; enhancement patterns and cryolesion size. BJU Int 2008;101:1237-42.

6. Uchida $\mathrm{M}$, Imaide $\mathrm{Y}$, Sugimoto $\mathrm{K}$, et al. Percutaneous cryosurgery for renal tumours. $\mathrm{Br} J \mathrm{Urol}$ 1995;75:132-6.
7. Chosy SG, Nakada SY, Lee FT Jr, et al. Monitoring renal cryosurgery: predictors of tissue necrosis in swine. J Urol 1998;159:1370-4.

8. Clarke DM, Robilotto AT, Rhee E, et al. Cryoablation of renal cancer: variables involved in freezing-induced cell death. Technol Cancer Res Treat 2007;6:69-79.

9. Clarke DM, Baust JM, Van Buskirk RG, et al. Chemo-cryo combination therapy: an adjunctive model for the treatment of prostate cancer. Cryobiology 2001;42:274-85.

10. Finley DS, Beck $S, B \times x G$, et al. Percutaneous and laparoscopic cryoablation of small renal masses. J Urol 2008; 180: 492.

11. Hinshaw JL, Shadid AM, Nakada SY, et al. Comparison of percutaneous and laparoscopic cryoablation for the treatment of solid renal masses. AJR Am J Roentgenol 2008;191:1159-68.

12. Davol PE, Fulmer BR, Rukstalis DB. Long-term results of cryoablation for renal cancer and complex renal masses. Urology 2006;68:(1 Suppl):2-6.

13. Weld KJ, Figenshau RS, Venkatesh R, et al. Laparoscopic cryoablation for small renal masses: three-year follow-up. Urology 2007;69:448-51.

14. Gill IS, Remer EM, Hasan WA, et al. Renal cryoablation: outcome at 3 years. J Urol 2005; 173: $1903-7$.

15. Celia A, Zeccolini $G$, Guazzoni $G$, et al. Laparoscopic nephron sparing surgery: a multi-institutional European survey of 592 cases. Arch Ital Urol Androl 2008;80:85-91.

16. Laguna MP, Beemster P, Kumar P, et al. Perioperative morbidity of laparoscopic cryoablation of small renal masses with ultrathin probes: a European multicentre experience. Eur Urol 2009;56:355-61.

17. Goel RK, Kaouk JH. Single port access renal cryoablation (SPARC): a new approach. Eur Urol 2008;53:1204-9.

18. Box G, Averch T, Cadeddu J, et al. Nomenclature of natural orifice translumenal endoscopic surgery (NOTES) and laparoendoscopic single-site surgery (LESS) procedures in urology. J Endourol 2008;22:2575-81.

19. Abouassaly R, Lane BR, Novick AC. Active surveillance of renal masses in elderly patients. I Urol 2008; 180:505-8.

20. Atwell $T D$, Farrell $M A$, Leibovich $B C$, et al. Percutaneous renal cryoablation: experience treating 115 tumours. J Urol 2008;179:2136-40.

21. Hui GC, Tuncali K, Tatti $S$, et al. Comparison of percutaneous and surgical approaches to renal tumour ablation: metaanalysis of effectiveness and complication rates. J Vasc Interv Radiol 2008;19:1311-20.

22. Badwan K, Maxwell K, Venkatesh R, et al. Comparison of laparoscopic and percutaneous cryoablation of renal tumours: a cost analysis. J Endourol 2008;22:1275-7.

23. Bandi G, Wen CC, Hedican SP, et al. Cryoablation of small renal masses: assessment of the outcome at one institution. BJU Int 2007;100:798-801.

24. Allaf ME, Lang E. Bowel separation before percutaneous renal cryoablation. J Urol 2008;180:721.

Correspondence: Dr. Joseph L. Chin, Room C3-120, Victoria Hospital, 800 Commissioners Rd East, P0 Box 5010, London, ON N6A 5W9; joseph.chin@LHSC.ON.CA 